Review Article

\title{
Vitamin D and Osteoporosis in HIV/HCV Coinfected Patients: A Literature Review
}

\author{
Paola Di Carlo, ${ }^{1}$ Lucia Siracusa, ${ }^{1}$ Giovanni Mazzola, ${ }^{2}$ Piero Colletti, ${ }^{2}$ Maurizio Soresi, ${ }^{2}$ \\ Lydia Giannitrapani, ${ }^{1}$ Valentina Li Vecchi, ${ }^{2}$ and Giuseppe Montalto ${ }^{2}$ \\ ${ }^{1}$ Department of Sciences for Health Promotion and Mother-Child Care "G. D’Alessandro", University of Palermo, \\ Via del Vespro 127, 90127 Palermo, Italy \\ ${ }^{2}$ Biomedical Department of Internal Medicine and Specialities, University of Palermo, Via del Vespro 141, 90127 Palermo, Italy
}

Correspondence should be addressed to Paola Di Carlo; paola.dicarlo@unipa.it

Received 11 October 2014; Revised 23 January 2015; Accepted 10 February 2015

Academic Editor: Ling-Qing Yuan

Copyright (c) 2015 Paola Di Carlo et al. This is an open access article distributed under the Creative Commons Attribution License, which permits unrestricted use, distribution, and reproduction in any medium, provided the original work is properly cited.

Vitamin D deficiency further increases the risk of osteoporosis in HIV-positive patients coinfected with hepatitis C virus (HCV); however, it is still unclear whether HCV-related increased fracture risk is a function of the severity of liver disease. The aim of this review was to identify studies on associative vitamin D deficiency patterns in high-risk populations such as HIV/HCV coinfected patients. We did this by searching MEDLINE and EMBASE databases, from inception to August 2014, and included bibliographies. The final 12 articles selected are homogeneous in terms of age but heterogeneous in terms of sample size, participant recruitment, and data source. Most of the HIV/HCV coinfected patients have less than adequate levels of vitamin D. After reviewing the selected articles, we concluded that vitamin D deficiency should be regarded as a continuum and that the lower limit of the ideal range is debatable. We found that vitamin D deficiency might influence liver disease progression in HIV/HCV coinfected patients. Methodological issues in evaluating vitamin D supplementation as a relatively inexpensive therapeutic option are discussed, as well as the need for future research, above all on its role in reducing the risk of HCV-related fracture by modifying liver fibrosis progression.

\section{Introduction}

Clinicians and researchers are currently using available data sets to assess the balance of beneficial and harmful effects of vitamin D not only on skeletal health but also on its potential role in nonskeletal outcomes such as cardiovascular disease, death, and quality of life [1-3].

The effects of vitamin D on immune function [4] and its immunomodulatory and anti-inflammatory properties have been recognized, and a nontraditional role of vitamin $\mathrm{D}$ has been reported in cancer patients and autoimmune disease [46].

These effects have also been reported in chronic liver disease and among chronic hepatitis $\mathrm{C}$ patients in whom vitamin $\mathrm{D}$ is involved in regulating the immune system, inflammatory response, and fibrogenesis [7-10].
Recently, low 25-Hydroxyvitamin D serum levels have been associated with the severity of liver fibrosis in genotype 1 chronic hepatitis $\mathrm{C}$ patients (G1CHC) $[11,12]$.

In vitro studies have shown that vitamin $\mathrm{D}$ is an antiviral agent that inhibits HCV production in a human hepatoma cell line [13]; a synergistic effect of vitamin D and interferonalfa on HCV production has also been reported. In HCV monoinfected patients with recurrent hepatitis $\mathrm{C}$ after liver transplant, higher rates of virologic response were observed in those receiving vitamin D supplementation [14].

Finally, in a randomized prospective trial including only $\mathrm{CHC}$ treatment-naive HCV-genotype (HCV-GT) 1 patients, virologic response rates were again higher in the group receiving vitamin $\mathrm{D}$ supplementation [11].

Hepatitis $\mathrm{C}$ virus (HCV) infection has become a major health problem among the HIV-infected population $[15,16]$. Approximately $30 \%$ of all human immunodeficiency virus 
(HIV-) positive patients are also infected with hepatitis $\mathrm{C}$ virus $(\mathrm{HCV})$ [16-18].

Among the multifactorial mechanisms underlying skeletal disorder in the HIV and HCV setting, vitamin D deficiency is considered a risk factor for osteoporotic fracture [7, 18-20]; moreover, the finding that HCV-related increased fracture risk is a function of the severity of liver disease has generated a lot of attention so far [7, 21-23].

The fact that HIV and HIV/HCV coinfected patients are at risk of vitamin $\mathrm{D}$ deficiency because a wide variety of medications used to treat AIDS/HIV enhance the catabolism of $25(\mathrm{OH}) \mathrm{D}$ and $1,25(\mathrm{OH}) 2 \mathrm{D}[23,24]$ has been acknowledged. Vitamin D deficiency and bone disease in HAART patients [25] have been associated with NNRTIs [26], as well as tenofovir [27] and PIs [27, 28].

While there are recommendations for the evaluation, treatment, and prevention of vitamin D deficiency in healthy patients at risk of deficiency $[3,24]$ and in specific HIV populations such as young HIV-positive adults with 25hydroxyvitamin D $(25-\mathrm{OHD})<20 \mathrm{ng} / \mathrm{mL}$ [29], there is still some debate about the evaluation, treatment, and prevention of vitamin D deficiency in the HIV population [30] and in particular in HIV/HCV coinfected subjects [7, 8, 31, 32].

Finally, recent literature offers recommendations on screening and treating vitamin D deficiency and osteoporosis in HIV-positive patients [30] but there is not a great deal of literature and/or consensus on cost-effective management of this patient population, especially $\mathrm{HIV} / \mathrm{HCV}$ coinfected patients [22, 31-33].

This paper aims to summarize the prevalence of vitamin $\mathrm{D}$ deficiency in $\mathrm{HIV} / \mathrm{HCV}$ coinfected patients, review available data on the association between vitamin $\mathrm{D}$ levels and severity of liver disease, and discuss the impact of this relatively inexpensive therapy on reducing liver fibrosis and improving sustained virologic response rate (SVR) in $\mathrm{HCV}$ patients.

\section{Methods}

We searched the Medline (PubMed) database for articles that matched any combination of the following keywords: vitamin $\mathrm{D}$, vitamin $\mathrm{D}$ deficiency, 25-hydroxyvitamin $\mathrm{D}$, $\mathrm{HIV} / \mathrm{HCV}$ coinfections and diagnosis and treatment, and hypovitaminosis. Studies were identified through searching MEDLINE and EMBASE databases, from their inception to August 2014.

Articles were screened and those that reported on the relationship between vitamin D insufficiency/deficiency and $\mathrm{HIV} / \mathrm{HCV}$ coinfections were included. We limited the search to language (i.e., Spanish, French, or English) and abstract availability. Because the terms HIV infection and HIV/HCV infection are frequently associated in the scientific literature, for this study the term $\mathrm{HIV} / \mathrm{HCV}$ coinfections was used as a medical subject heading $(\mathrm{MeSH})$ and the other terms (together with their linguistic variations) were used as keywords. Some articles that appeared with keyword searching were excluded because they were not relevant to the purpose of this review and tackled other topics such as anti-HCV therapy in $\mathrm{HIV} / \mathrm{HCV}$ coinfected patients.

\section{Results}

Forty-four studies fit the criteria; 15 of these were duplicates and were removed. After screening titles and abstracts, we excluded 9 articles on studies involving HCV monoinfected or HIV monoinfected participants. Applying the eligibility criteria, the full texts of 12 articles were reviewed.

We selected 12 studies (see Table 1): 10 original [21, 3139], 1 systematic review and meta-analysis article [22], and 1 review manuscript [20].

We found 5 cross-sectional [31, 32, 35, 37, 39], 3 retrospective $[21,34,36]$, and 2 prospective cohort studies $[33,38]$; most control groups included patients with HIV-mono- or HCV-monoinfection.

Overall, the articles were highly heterogeneous in terms of sample size, participant recruitment, and data source (Table 1). The patients' age in all the studies is relatively homogenous (median age 45 years old), reflecting the worldwide aging of the HIV population after the widespread availability of combination antiretroviral therapy (cART).

In general, the articles analyzed the prevalence of vitamin D levels in HIV/HCV coinfected patients and the association between vitamin D deficiency and liver disease variables such as severity of liver disease $[21,32,34,39]$ and the influence of vitamin $\mathrm{D}$ levels on virological response $[32,35,36]$.

In fact, two recent studies showed a significant association between hypovitaminosis $\mathrm{D}$, severity of liver disease, and response to interferon- (IFN-) based treatment in HIV-HCV patients $[11,35]$. However, the association between $25(\mathrm{OH}) \mathrm{D}$ levels and SVR rates is thought to be limited to difficult-totreat patients in whom treatment failure may depend on other factors (IL28 B, HCV genotype, hepatic expression of vitamin $\mathrm{D}$ receptor) $[11,12,33,35]$.

In their HIV/HCV coinfected setting, Branch et al. [36] found that baseline levels of 25(OH)D in patients treated with ritonavir are not predictors of EVR and SVR because ritonavir may influence conversion of $25(\mathrm{OH}) \mathrm{D}$ to the active metabolite. Other articles showed a significant negative association between longer duration of ART, especially PI exposure and bone mineral density (BMD) and osteoporosis [22, 28, 38]. However, in one large cohort study, HCV coinfection remained an independent predictor of osteoporotic fractures after checking for the presence of cirrhosis [21, 22].

Two articles [33, 39] showed no association between hypovitaminosis $\mathrm{D}$, low BMD, and liver fibrosis (histological fibrosis staging according to METAVIR scores 0 [no fibrosis] to 4 [cirrhosis]) in HIV/HCV coinfected patients. The analysis of patient setting showed that most of the study populations included $\mathrm{HIV} / \mathrm{HCV}$ coinfected African Americans. How race affects the impact of vitamin $\mathrm{D}$ on bone health has recently been investigated in African American men and women, revealing differences due to socioeconomic and genetic factors, such as resistance to the bone resorbing effects of PTH in the black population [33, 40-42]. 


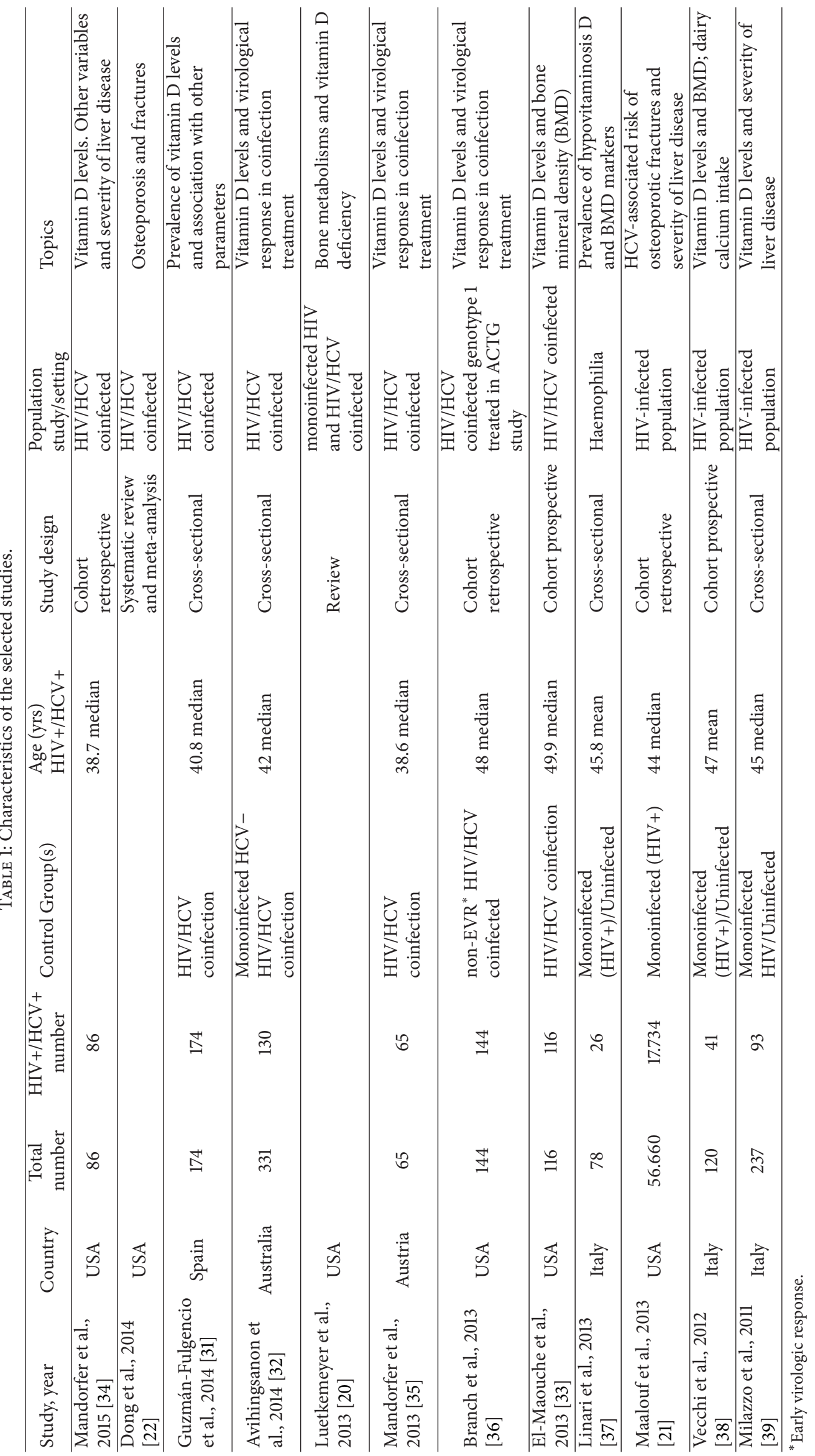


Most of the patients enrolled in Milazzo et al.s study [39] had HCV GT1 genotype and low levels of vitamin D that varied seasonally, as reported in another Italian study [9].

On the contrary, Avihingsanon et al. [32] found significant liver fibrosis in patients with $\mathrm{HIV} / \mathrm{HCV}$ coinfection and low levels of $25(\mathrm{OH}) \mathrm{D}$. These results may be influenced by race (Asian), HCV genotype (GT) [the most prevalent circulating genotype was HCV GT3 (47\%)], and IL28B polymorphism (the major allele [CC genotype] of rs12979860 position was found in $88 \%$ of $\mathrm{HIV} / \mathrm{HCV}$ patients).

Regarding the prevalence of fracture in this group of patients with liver disease, Dong et al's systematic review and meta-analysis [22] highlights that fracture incidence rate ratios (IRRs) are higher for coinfected than HIV monoinfected and uninfected patients. In multivariate analyses of $\mathrm{HIV} / \mathrm{HCV}$ coinfected individuals, older age, lower BMI, postmenopausal status, and time on protease inhibitor were significantly associated with osteoporosis $[18-20,22,27,28$, 38].

Among the HIV/HCV coinfected patients, haemophiliacs are considered to be at the highest risk for fracture. Table 1 includes Linari et al.s study [37] on the prevalence of osteoporosis in this group of patients. The authors divided 78 haemophiliac patients into three groups (uninfected, HIV monoinfected, and HIV/HCV coinfected); hypovitaminosis $\mathrm{D}$ and low BMD were present in all patients, with lower L-DXA scores in coinfected patients and a more evident increase of bone resorption markers in HIV and HIV/HCV coinfected patients.

\section{Discussion}

Our literature review indicated that vitamin D deficiency is common in HIV/HCV coinfected patients and that hypovitaminosis $\mathrm{D}$ occurrence among patients with an average age of 45 years should raise concerns about the risk of developing bone fractures.

Low levels of vitamin D were also found in HIV monoinfected [21, 38, 39] and HCV monoinfected control groups $[32,37]$.

However, the selected articles reveal some aspects that prompt us to reconsider the definition of hypovitaminosis D. In fact, the significance of vitamin $\mathrm{D}$ deficiency has several limitations because 25-hydroxyvitamin D concentrations varied by age, season, study sample size, and methodological assay approach [25(OH)D assay used] [37, 39, 40]. Moreover, black and Hispanic individuals synthesize less vitamin D per unit of sun exposure than white individuals [33, 41, 42]. Therefore, levels of vitamin D in HIV/HCV coinfected patients should be monitored according to the reference range for the sample setting. In fact, further validation of the reported results is needed, since studies conducted on larger cohorts, as well as in Italian coinfected patients [39], have revealed low vitamin $\mathrm{D}$ levels consistent with those recently reported for healthy populations from Western countries $[38,39,43]$.

Milazzo et al. found that season and severity of fibrosis were predictors of low 25(OH)D in an Italian $\mathrm{HIV} / \mathrm{HCV}$ coinfected population and that median 25(OH)D serum levels below $25 \mathrm{ng} / \mathrm{mL}$ were similar in the HIV monoinfected, HIV/HCV coinfected, and healthy controls [39]. In a recent, large study on a general healthy population in Central Europe, Pludowski et al. [43] reported an average concentration of less than $30 \mathrm{ng} / \mathrm{mL}$ of $25(\mathrm{OH}) \mathrm{D}$.

Guidelines specify that $25(\mathrm{OH}) \mathrm{D}$ concentrations are the best indicator of overall vitamin $\mathrm{D}$ status in the general population and define vitamin D insufficiency as a $25(\mathrm{OH}) \mathrm{D}$ level of below $75 \mathrm{nmol} / \mathrm{L}(30 \mathrm{ng} / \mathrm{mL})$ and deficiency as below $50 \mathrm{nmol} / \mathrm{L}$ (20 ng/mL) [40]. However, the Endocrine Society Clinical Practice Guidelines (ESCPG) suggest that the vitamin $D$ requirements of sick patients may be greater than those of healthy individuals, and blood levels above $30 \mathrm{ng} / \mathrm{mL}$ may carry additional health benefits by reducing the risk of various disease conditions [24, 40].

The Hormone Foundation's Patient Guide to Vitamin D Deficiency suggests that patients with chronic (long-term) liver disease are at high risk of deficiency; therefore vitamin D testing is recommended and patients should be given advice about adequate dietary intake and medical supplementation to prevent and treat deficiency [44].

The influence of diet on vitamin $\mathrm{D}$ status is minimal (accounting for 3.7-5.9 $\mu \mathrm{g}$ or 148-236 IU daily) as only a few foods, such as sardines, tuna, and mushrooms, naturally contain vitamin D $[24,40]$. Today, the main sources are foods which have been fortified with vitamin D2 and/or vitamin D3, such as milk, orange juice, yoghurt, cheese, and breakfast cereals, which people of all ages can include in their daily diet. Although it has been suggested that a Mediterraneanstyle diet or a diet rich in fish and other foods containing vitamin $\mathrm{D}$ has health benefits, further evaluation is necessary [24, 38, 44, 45].

Our selected articles investigated the possibility of an association between vitamin D deficiency and hepatic fibrosis in $\mathrm{HIV} / \mathrm{HCV}$ coinfected patients. One particular study that involved mostly African American HIV-HCV coinfected patients showed that increasing vitamin $\mathrm{D}$ levels does not improve bone or liver outcome [33], whereas other studies illustrate how vitamin $\mathrm{D}$ influences virological response to antiviral treatment in HIV-HCV coinfected patients and has a role in liver fibrosis progression $[31,34,35]$.

Older and more recent research has investigated the link between vitamin $\mathrm{D}$ homeostasis and bone loss in patients with liver disease $[7,8,22,46]$. Vitamin $\mathrm{D}$ deficiency in chronic liver disease is only partly the result of a synthesis dysfunction of the liver or/and decreased vitamin D absorption caused by intestinal edema due to portal hypertension or to cholestasis.

Recently, significantly lower levels of 25-hydroxyvitamin $\mathrm{D}$ were observed in patients with liver cirrhosis, admitted for acute decompensation, suggesting that systemic inflammation or liver dysfunction has an impact on 25(OH)D level [46].

Regarding vitamin D synthesis, parathyroid hormone (PTH) is involved in its activity and expression; disturbance of the parathyroid hormone-vitamin $\mathrm{D}$ axis with bone mass loss in chronic liver disease has recently been reported in 
cirrhotic postmenopausal women and in geriatric patients with vitamin D deficiency $[47,48]$.

A systematic review and meta-analysis included in our literature review found that $\mathrm{HIV} / \mathrm{HCV}$-coinfected patients are at higher risk for osteoporosis and fractures than HIVmonoinfected controls and are at a substantially higher risk than uninfected controls. HCV and viral hepatitis coinfection remained an independent predictor of osteoporosis [22].

HCV and HIV infections are both associated with increased levels of proinflammatory cytokines that can promote osteoclastogenesis or inhibit osteoblast differentiation and collagen synthesis $[7,8,22]$.

The mechanisms responsible for osteopenia and osteoporosis are uncertain and multifactorial, but exposure to certain antiretroviral drugs (in particular a NRTI: tenofovirTDF-and the PI class), aging, HIV itself, parathormone (PTH) increase, and vitamin D deficiency may be implicated.

Moreover, in a cohort of G1CHC patients, the hepatic expression of VDR protein is associated with severity of both liver fibrosis and inflammation [12, 34].

Guidelines for the management of osteoporosis in HIVnegative $[3,24,40,44]$ and HIV-positive patients identified adequate vitamin $\mathrm{D}$ status, in addition to calcium from diet or supplements, as essential for the prevention of osteoporosis $[24,29,30,49]$. Adjunct therapy with high-dose, daily vitD3 for HIV-infected subjects and for those on/off highly active antiretroviral therapy was recently investigated in a highrisk, adult HIV-infected group and in HIV-infected children $[29,49]$. However, these levels have not been supported by adequate dose-finding RTC studies.

Our review highlights important areas to explore for future prevention strategies. Future interferon-free directacting agents may have a better effect on bone metabolism and decrease fracture incidence after successful treatment. Although the risk of fracture is clearly higher in $\mathrm{HIV} / \mathrm{HCV}$ coinfected individuals, it is not clear if DXA screening of these individuals before the age of 50 is a cost-effective prevention method and requires further study.

Lifestyle-related factors appear to have a substantial impact on the risk of fractures in $\mathrm{HIV} / \mathrm{HCV}$ coinfected individuals but, based upon available studies, this cannot solely be attributed to alcohol and substance use [22, 38].

Recent data indicate that vitamin D supplementation is a relatively inexpensive therapeutic option to reduce liver fibrosis and improve SVR $[22,34]$. Interestingly, two potentially modifiable factors, CD4+ nadir and serum $25(\mathrm{OH}) \mathrm{D}$ levels, were both independent modulators of liver fibrosis progression and determinants of portal pressure [34].

Currently, practitioners are often concerned about the lack of well-characterized data on the therapeutic value of vitamin D supplementation to reduce liver fibrosis progression in $\mathrm{HIV} / \mathrm{HCV}$ coinfected patients. Increasing vitamin $\mathrm{D}$ intake may positively modulate response to antiviral treatment in HCV-infected or HIV/HCV coinfected patients, and, in association with standardized treatment for chronic liver disease, it could be of benefit in reducing liver fibrosis progression in $\mathrm{HIV} / \mathrm{HCV}$ coinfected patients.
In general, there is no evidence to suggest that increasing the recommended vitamin $\mathrm{D}$ intake for the general population to $20-50 \mu \mathrm{g}(800-2000 \mathrm{IU})$ would cause any medical problems. However, the authors recommend careful clinical observation and laboratory monitoring when higher doses of vitamin $\mathrm{D}$ supplements are administered because of the long half-life of vitamin D accumulation in tissues; excessive intake of vitamin D can cause chronic toxic effects, which present ashypercalcemia and renal damage.

Further controlled randomized trials on the effects of vitamin D supplementation are warranted to assess the relevance of vitamin $\mathrm{D}$ for liver fibrosis progression in $\mathrm{HIV} / \mathrm{HCV}$ coinfected patients.

\section{Conclusions}

Our review indicates that vitamin D supplementation can be considered a relatively inexpensive therapeutic option to lower HCV-related fracture risk, owing to its benefic effect in reducing liver fibrosis progression in $\mathrm{HIV} / \mathrm{HCV}$ coinfected patients. Other determinants of $\mathrm{HCV}$-related increased fracture risk have still to be defined.

A good compromise between different opinions could be to start with relatively higher doses of vitamin $\mathrm{D}$ in HIV-HCV infected patients, skipping some steps of dose supplementation until more information is available to settle the question.

\section{What Is New?}

What Is Known?

(i) Experimental evidence suggested a hepatoprotective role of vitamin D.

(ii) Practitioners are often concerned about the lack of well-characterized data on the therapeutic value of Vitamin D supplementation to reduce liver fibrosis progression in $\mathrm{HIV} / \mathrm{HCV}$ coinfected patients.

What Is New?

(i) Only particularly low levels of vitamin D should be considered in HIV/HCV coinfected patients.

(ii) This systematic review reveals a recent interest in vitamin D supplementation as a relatively inexpensive therapeutic option to reduce HCV-related increased fracture risk by modifying liver fibrosis progression.

What Does This Mean?

(i) Among HIV-infected patients, the association between $25(\mathrm{OH}) \mathrm{D}$ levels and severity of liver disease partly explains the $\mathrm{HCV}$-associated increased risk of osteoporotic fractures, while other determinants have still to be defined.

(ii) Further RCTs are warranted to determine what level of vitamin D insufficiency and deficiency places an individual at risk of cirrhosis evolutions and what is the optimal dosage of vitamin D3 to exert sufficient antifibrosis effects in HIV/HCV coinfected populations. 


\section{Conflict of Interests}

The authors state that there are no conflict of interests and that they have not received any payment for the preparation of this paper.

\section{References}

[1] L. Langsetmo, C. Berger, N. Kreiger et al., "Calcium and Vitamin D intake and mortality: results from the Canadian Multicentre Osteoporosis Study (CaMos)," Journal of Clinical Endocrinology and Metabolism, vol. 98, no. 7, pp. 3010-3018, 2013.

[2] V. A. Moyer, "Vitamin, mineral, and multivitamin supplements for the primary prevention of cardiovascular disease and cancer: U.S. Preventive services Task Force recommendation statement," Annals of Internal Medicine, vol. 160, no. 8, pp. 558564,2014

[3] D. A. Hanley, A. Cranney, G. Jones et al., "Guidelines committee of the scientific advisory council of osteoporosis canada," Canadian Medical Association Journal, vol. 182, no. 12, pp. E610E618, 2010.

[4] M. Hewison, "Vitamin D and immune function: an overview," Proceedings of the Nutrition Society, vol. 71, no. 1, pp. 50-61, 2012.

[5] S. Roy, K. Shrinivas, and B. Bagchi, "A stochastic chemical dynamic approach to correlate autoimmunity and optimal vitamin-D range," PLoS ONE, vol. 9, no. 6, Article ID el00635, 2014.

[6] P. E. Pfeffer, E. H. Mann, E. Hornsby et al., "Vitamin D influences asthmatic pathology through its action on diverse immunological pathways," Annals of the American Thoracic Society, vol. 11, supplement 5, pp. S314-S321, 2014.

[7] P. Iruzubieta, Á. Terán, J. Crespo, and E. Fábrega, "Vitamin D deficiency in chronic liver disease," World Journal of Hepatology, vol. 6, no. 12, pp. 901-915, 2014.

[8] Y.-Q. Luo, X.-X. Wu, Z.-X. Ling, Y.-W. Cheng, L. Yuan, and C. Xiang, "Association between serum vitamin D and severity of liver fibrosis in chronic hepatitis $C$ patients: a systematic metaanalysis," Journal of Zhejiang University SCIENCE B, vol. 15, no. 10, pp. 900-906, 2014.

[9] S. Petta, S. Grimaudo, V. D. Marco et al., "Association of vitamin $\mathrm{D}$ serum levels and its common genetic determinants, with severity of liver fibrosis in genotype 1 chronic hepatitis $\mathrm{C}$ patients," Journal of Viral Hepatitis, vol. 20, no. 7, pp. 486-493, 2013.

[10] B. Terrier, F. Carrat, G. Geri et al., "Low 25-OH vitamin D serum levels correlate with severe fibrosis in HIV-HCV co-infected patients with chronic hepatitis," Journal of Hepatology, vol. 55, no. 4, pp. 756-761, 2011.

[11] S. Abu-Mouch, Z. Fireman, J. Jarchovsky, A.-R. Zeina, and N. Assy, "Vitamin D supplementation improves sustained virologic response in chronic hepatitis C (genotype 1)-naïve patients," World Journal of Gastroenterology, vol. 17, no. 47, pp. 5184-5190, 2011.

[12] S. Petta, S. Grimaudo, C. Tripodo et al., “The hepatic expression of vitamin d receptor is inversely associated with the severity of liver damage in genotype 1 chronic hepatitis $\mathrm{C}$ patients," The Journal of Clinical Endocrinology \& Metabolism, vol. 100, no. 1, pp. 193-200, 2015.

[13] M. Gal-Tanamy, L. Bachmetov, A. Ravid et al., "Vitamin D: an innate antiviral agent suppressing hepatitis $\mathrm{C}$ virus in human hepatocytes," Hepatology, vol. 54, no. 5, pp. 1570-1579, 2011.
[14] D. Bitetto, C. Fabris, E. Fornasiere et al., "Vitamin D supplementation improves response to antiviral treatment for recurrent hepatitis C," Transplant International, vol. 24, no. 1, pp. 43-50, 2011.

[15] J. K. Rockstroh, A. Mocroft, V. Soriano et al., "Influence of hepatitis $\mathrm{C}$ virus infection on HIV-1 disease progression and response to highly active antiretroviral therapy," Journal of Infectious Diseases, vol. 192, no. 6, pp. 992-1002, 2005.

[16] K. E. Sherman, S. D. Rouster, R. T. Chung, and N. Rajicic, "Hepatitis C virus prevalence among patients infected with human immunodeficiency virus: a cross-sectional analysis of the US adult AIDS Clinical Trials Group," Clinical Infectious Diseases, vol. 34, no. 6, pp. 831-837, 2002.

[17] C. T. Staples Jr., D. Rimland, and D. Dudas, "Hepatitis C in the HIV (Human Immunodeficiency Virus) Atlanta V.A. (Veterans Affairs Medical Center) cohort study (HAVACS): the effect of coinfection on survival," Clinical Infectious Diseases, vol. 29, no. 1, pp. 150-154, 1999.

[18] A. Bonjoch, M. Figueras, C. Estany et al., "Osteoporosis Study Group. High prevalence of and progression to low bone mineral density in HIV-infected patients: a longitudinal cohortstudy," AIDS, vol. 24, no. 18, pp. 2827-2833, 2010.

[19] V. A. Triant, T. T. Brown, H. Lee, and S. K. Grinspoon, "Fracture prevalence among human immunodeficiency virus (HIV)infected versus non-HIV-infected patients in a large U.S. healthcare system," The Journal of Clinical Endocrinology and Metabolism, vol. 93, no. 9, pp. 3499-3504, 2008.

[20] A. F. Luetkemeyer, D. V. Havlir, and J. S. Currier, "CROI 2013: complications of HIV disease, viral hepatitis, and antiretroviral therapy," Topics in Antiviral Medicine, vol. 21, no. 2, pp. 62-74, 2013.

[21] N. M. Maalouf, S. Zhang, H. Drechsler, G. R. Brown, P. Tebas, and R. Bedimo, "Hepatitis C Co-infection and severity of liver disease as risk factors for osteoporotic fractures among HIVinfected patients," Journal of Bone and Mineral Research, vol. 28, no. 12, pp. 2577-2583, 2013.

[22] H. V. Dong, Y. I. Cortés, S. Shiau, and M. T. Yin, “Osteoporosis and fractures in HIV/hepatitis $\mathrm{C}$ virus coinfection: a systematic review and meta-analysis," AIDS, vol. 28, no. 14, pp. 2119-2131, 2014.

[23] C. Zhou, M. Assem, J. C. Tay et al., "Steroid and xenobiotic receptor and vitamin D receptor crosstalk mediates CYP24 expression and drug-induced osteomalacia," The Journal of Clinical Investigation, vol. 116, no. 6, pp. 1703-1712, 2006.

[24] M. F. Holick, N. C. Binkley, H. A. Bischoff-Ferrari et al., "Evaluation, treatment, and prevention of vitamin D deficiency: an endocrine society clinical practice guideline," The Journal of Clinical Endocrinology and Metabolism, vol. 96, no. 7, pp. 19111930, 2011.

[25] E. Ramayo, M. P. González-Moreno, J. Macías et al., "Relationship between osteopenia, free testosterone, and vitamin D metabolite levels in HIV-infected patients with and without highly active antiretroviral therapy," AIDS Research and Human Retroviruses, vol. 21, no. 11, pp. 915-921, 2005.

[26] K. Gyllensten, F. Josephson, K. Lidman, and M. Sääf, “Severe vitamin D deficiency diagnosed after introduction of antiretroviral therapy including efavirenz in a patient living at latitude 59 degrees," AIDS, vol. 20, no. 14, pp. 1906-1907, 2006.

[27] K. Childs, C. Kadish, W. Branch-Elliman, S. Fishman, M. Mullen, and A. Branch, "Vitamin D and calcium supplements reverse the secondary hyperparathyroidism that commonly 
occurs in HIV patients on TDF containing HAART,' in Proceedings of the 15th Annual Conference of the British HIV Association, vol. 10, p. 40, HIV Medication, Liverpool, UK, 2009, Abstract P89.

[28] P. Rivas, M. Górgolas, R. García-Delgado, M. Díaz-Curiel, A. Goyenechea, and M. L. Fernández-Guerrero, "Evolution of bone mineral density in AIDS patients on treatment with zidovudine/lamivudine plus abacavir or lopinavir/ritonavir," HIV Medicine, vol. 9, no. 2, pp. 89-95, 2008.

[29] P. L. Havens, K. Mulligan, R. Hazra et al., "Serum 25-hydroxyvitamin D response to vitamin D3 supplementation 50,000 IU monthly in youth with HIV-1 infection," Journal of Clinical Endocrinology and Metabolism, vol. 97, no. 11, pp. 4004-4013, 2012.

[30] V. W. Harris and T. T. Brown, "Bone loss in the HIV-infected patient: evidence, clinical implications, and treatment strategies," The Journal of Infectious Diseases, vol. 205, no. 3, pp. S391S398, 2012.

[31] M. Guzmán-Fulgencio, M. García-Álvarez, J. Berenguer et al., "Vitamin D deficiency is associated with severity of liver disease in HIV/HCV coinfected patients," Journal of Infection, vol. 68, no. 2, pp. 176-184, 2014.

[32] A. Avihingsanon, S. Jitmitraparp, P. Tangkijvanich et al., "Advanced liver fibrosis by transient elastography, Fibrosis 4, and alanine aminotransferase/platelet ratio index among Asian hepatitis $\mathrm{C}$ with and without human immunodeficiency virus infection: role of vitamin D levels," Journal of Gastroenterology and Hepatology, vol. 29, no. 9, pp. 1706-1714, 2014.

[33] D. El-Maouche, S. H. Mehta, C. G. Sutcliffe et al., "Vitamin D deficiency and its relation to bone mineral density and liver fibrosis in HIV-HCV coinfection," Antiviral Therapy, vol. 18, no. 2, pp. 237-242, 2013.

[34] M. Mandorfer, B. A. Payer, P. Schwabl et al., "Revisiting liver disease progression in HIV/HCV-coinfected patients: the influence of vitamin D, insulin resistance, immune status, IL28B and PNPLA3," Liver International, vol. 35, no. 3, pp. 876-885, 2015.

[35] M. Mandorfer, T. Reiberger, B. A. Payer et al., "Low vitamin $\mathrm{D}$ levels are associated with impaired virologic response to PEGIFN+RBV therapy in HIV-hepatitis C virus coinfected patients," AIDS, vol. 27, no. 2, pp. 227-232, 2013.

[36] A. D. Branch, M. Kang, K. Hollabaugh, C. M. Wyatt, R. T. Chung, and M. J. Glesby, "In HIV/hepatitis C virus coinfected patients, higher 25-hydroxyvitamin D concentrations were not related to hepatitis $C$ virus treatment responses but were associated with ritonavir use," The American Journal of Clinical Nutrition, vol. 98, no. 2, pp. 423-429, 2013.

[37] S. Linari, G. Montorzi, D. Bartolozzi et al., "Hypovitaminosis $\mathrm{D}$ and osteopenia/osteoporosis in a haemophilia population: a study in HCV/HIV or HCV infected patients," Haemophilia, vol. 19, no. 1, pp. 126-133, 2013.

[38] V. L. Vecchi, M. Soresi, L. Giannitrapani et al., "Dairy calcium intake and lifestyle risk factors for bone loss in hiv-infected and uninfected mediterranean subjects," BMC Infectious Diseases, vol. 12, article 192, 2012.

[39] L. Milazzo, C. Mazzali, G. Bestetti et al., "Liver-related factors associated with low vitamin D levels in HIV and HIV/HCV coinfected patients and comparison to general population," Current HIV Research, vol. 9, no. 3, pp. 186-193, 2011.

[40] M. F. Holick, N. C. Binkley, H. A. Bischoff-Ferrari et al., "Guidelines for preventing and treating vitamin D deficiency and insufficiency revisited," Journal of Clinical Endocrinology and Metabolism, vol. 97, no. 4, pp. 1153-1158, 2012.
[41] F. Cosman, D. C. Morgan, J. W. Nieves et al., "Resistance to bone resorbing effects of PTH in black women," Journal of Bone and Mineral Research, vol. 12, no. 6, pp. 958-966, 1997.

[42] G. B. Taksler, D. M. Cutler, E. Giovannucci, and N. L. Keating, "Vitamin D deficiency in minority populations," Public Health Nutrition, vol. 15, pp. 1-13, 2014.

[43] P. Pludowski, W. B. Grant, H. P. Bhattoa et al., "Vitamin D status in central Europe," International Journal of Endocrinology, vol. 2014, Article ID 589587, 12 pages, 2014.

[44] M. F. Holick and C. M. Gordon, “The hormone foundation's: patient guide to vitamin D deficiency," The Journal of Clinical Endocrinology and Metabolism, vol. 96, no. 7, pp. 1-2, 2011.

[45] J. F. Calderon-Garcia, J. M. Moran, R. Roncero-Martin, P. ReySanchez, F. J. Rodriguez-Velasco, and J. D. Pedrera-Zamorano, "Dietary habits, nutrients and bone mass in Spanish premenopausal women: the contribution of fish to better bone health," Nutrients, vol. 5, no. 1, pp. 10-22, 2012.

[46] M. Costa Silva, T. Erotides Silva, M. L. Alentar et al., "Factors associated with 25-hydroxyvitamin D levels in patients with liver cirrhosis," Annals of Hepatology, vol. 14, no. 1, pp. 99-107, 2015.

[47] J. L. González-Calvin, J. L. Mundi, F. J. Casado-Caballero, A. C. Abadia, and J. J. Martin-Ibañez, "Bone mineral density and serum levels of soluble tumor necrosis factors, estradiol, and osteoprotegerin in postmenopausal women with cirrhosis after viral hepatitis," The Journal of Clinical Endocrinology \& Metabolism, vol. 94, no. 12, pp. 4844-4850, 2009.

[48] M. P. Björkman, A. J. Sorva, J. Risteli, and R. S. Tilvis, "Low parathyroid hormone levels in bedridden geriatric patients with vitamin D deficiency," Journal of the American Geriatrics Society, vol. 57, no. 6, pp. 1045-1050, 2009.

[49] V. A. Stallings, J. I. Schall, M. L. Hediger et al., "High-dose vitamin D3 supplementation in children and young adults with HIV: a randomized, placebo-controlled trial," The Pediatric Infectious Disease Journal. In press. 


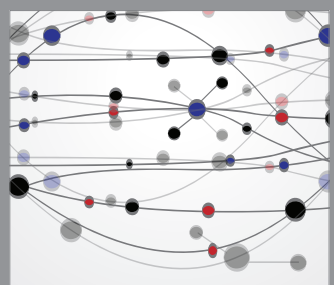

The Scientific World Journal
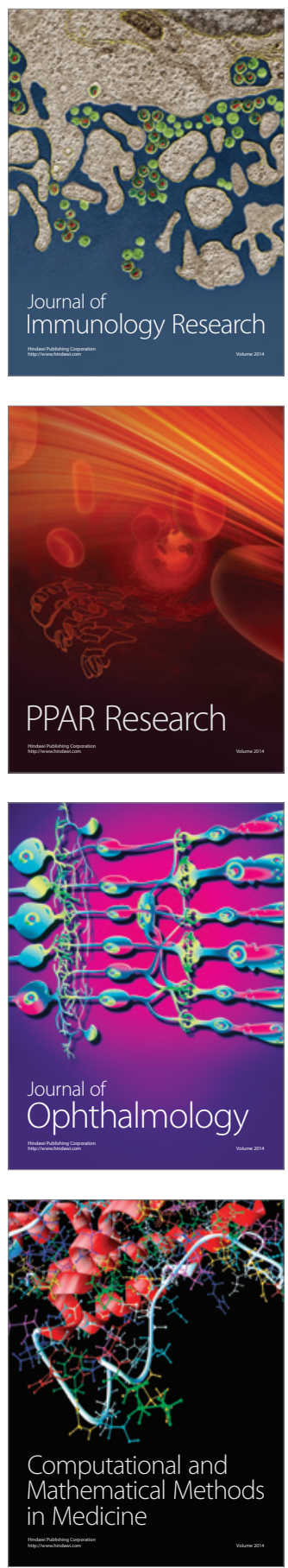

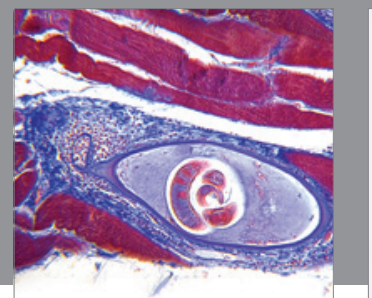

Gastroenterology

Research and Practice
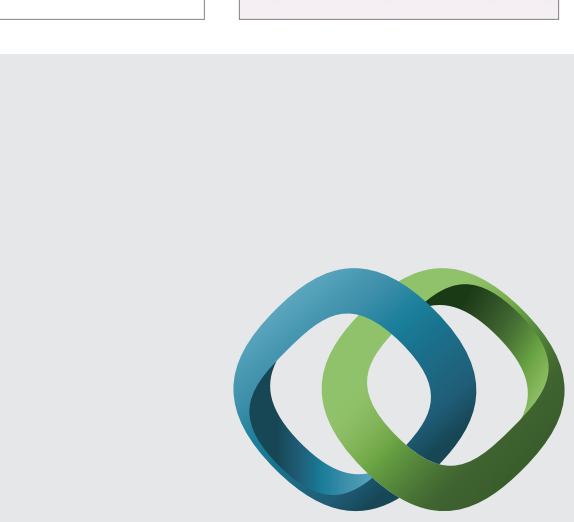

\section{Hindawi}

Submit your manuscripts at

http://www.hindawi.com
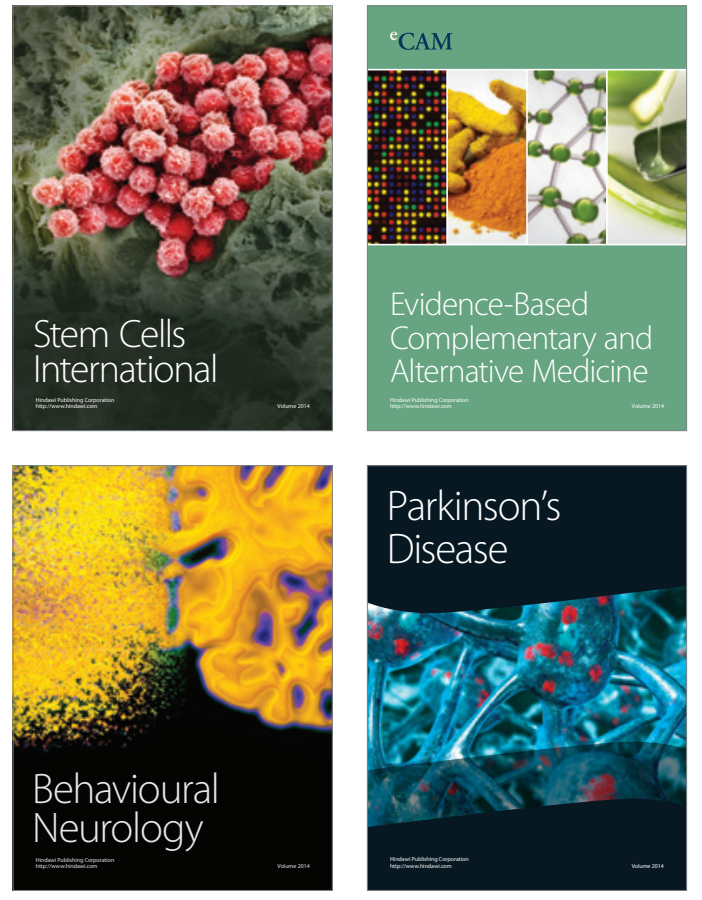
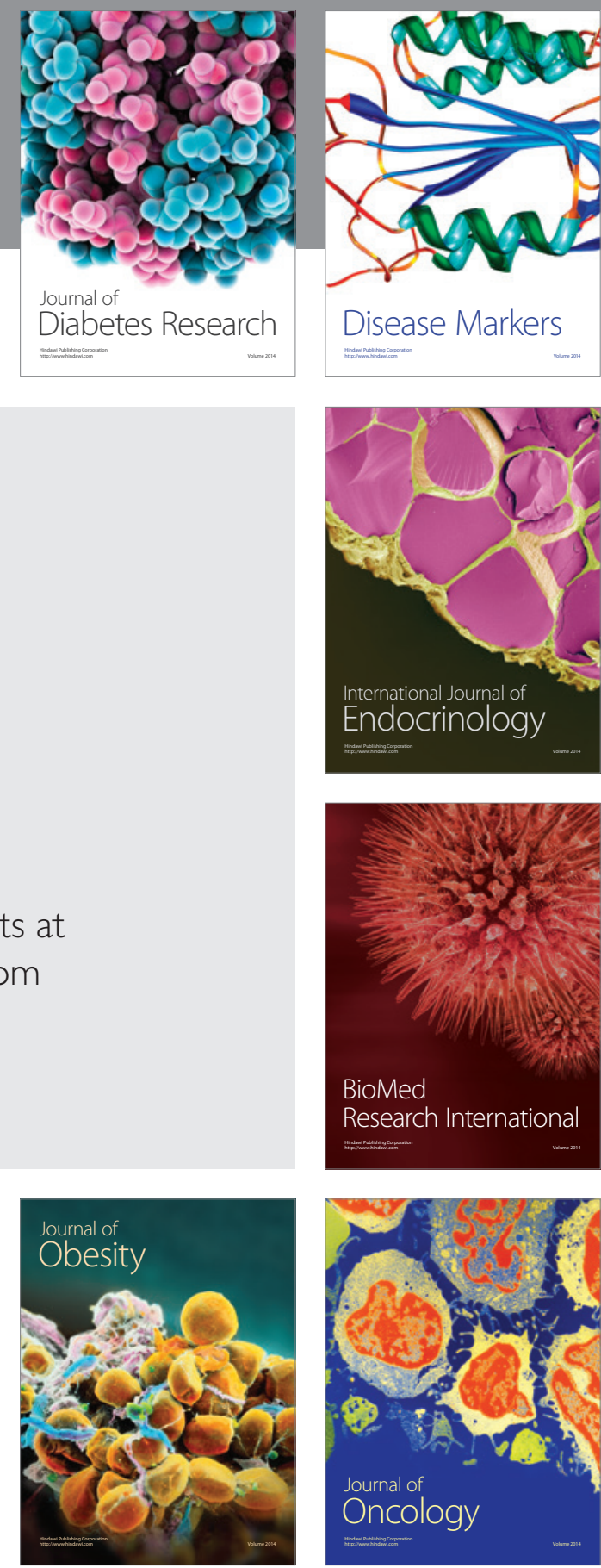

Disease Markers
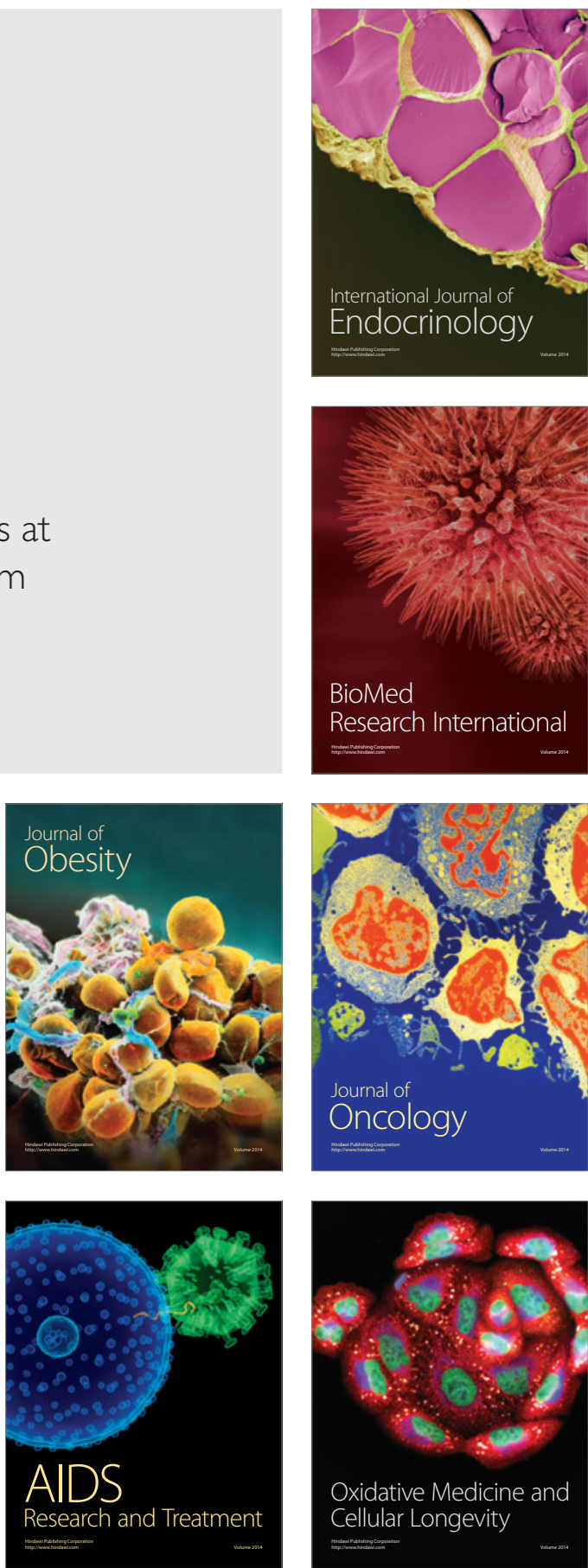